\title{
A Study on Use of Recycled Polyethylene Terephthalate (PET) as Construction Material
}

\author{
Brajesh Mishra \\ M. Tech., Assistant Engineer, U.P. Cane Development Department, Lucknow, India
}

\begin{abstract}
The trend of annual consumption of various types of plastics is increasing tremendously all over the world. Huge quantities of plastic wastes are generated as a result of various manufacturing processes, industries and municipal solid wastes (MSW). This has created an alarming situation for disposal of waste plastics in an eco-friendly way to protect the environment. In present scenario the management of disposal of solid wastes has become an important and vital issue across the world. It is due to scarcity of landfills and also increasing cost of disposal of waste plastic materials, has compelled to utilize the waste plastics in construction activities for its safe disposal. This study summarizes the experimental efforts on use of polyethylene terephathalate (PET) in road construction and cement

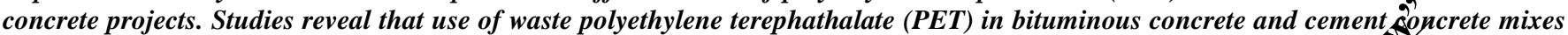
resulted in improvement of certain properties and also in the economy of the cost. The use of new polymeric materials ber beduced by
\end{abstract} using polyethylene terephathalate (PET) in building materials avoiding adverse effect on environment.

Keywords: Bituminous concrete, building materials, cement concrete, polyethylene terephathalate (PET), recyclin\%.

\section{Introduction}

Plastics play very important role in every aspect of our life. The waste generated from plastic articles has to be disposed in an eco-friendly way to avoid any environmental pollution. The highest content of plastic is present in containers and packaging material i.e. bottles, packaging, cups etc. Plastice are also present in articles like tires, building materjals, furniture etc. and disposable medical devices. The of plastic material is dependent on its specific noperties mentioned as below;

- Low density, easy processing,

- Good mechanical properties and chemical resis

- Low cost in comparison to other materials

Waste plastic can be utilized in many two main direction should be mentioned:

- Using of plastic waste as alternati tuent centent kilns and power plants and

- Material recycling of waste

The municipal solid waste 9 Senerated in U.S. is about 200 Mega tons per year. S. Environmental Protection Agency (USEPA 1982) consists of about 38\% paper product, $8 \%$ pl $3 \%$ carpet and textiles. In 1996 content of plastre ran to $12 \%$ in MSW. The world's annual consumption of plastic material has increased from 204 million tons in the 2002 to around 300 million tons in 2013. Moreover, production and consumption of polymers and plastics will be constantly growing in next year. The details are given in table- 1 .

Table 1: Types and quantity of plastics in MSW in U.S.A

\begin{tabular}{|l|c|}
\hline \multicolumn{1}{|c|}{ Type of plastic } & Quantity in tons \\
\hline Low density polyethylene (LDPE) & 5010000 \\
\hline High density polyethylene (HDPE) & 4120000 \\
\hline Polypropylene (PP) & 2580000 \\
\hline Polyethylene terephathalate (PET) & 1700000 \\
\hline Others & 3130000 \\
\hline
\end{tabular}

Table 2: Thermosetting and Thermoplastic materials

\begin{tabular}{|l|l|}
\hline \multicolumn{1}{|c|}{ Thermoplastics } & \multicolumn{1}{c|}{ Thermosetting } \\
\hline Polyethylene terephathalate (PET) & Bakelite \\
\hline Polypropylene (PP) & Epoxy resin \\
\hline Polyvinyl acetate (PVA) & Melamine resin \\
\hline Polyvinyl Chloride (PVC) & Polyester \\
\hline Polystyrene(PS) & Polyurethane \\
\hline Low density polyethylene (LDPE) & Urea- Formaldehyde \\
\hline High density polyethylene (HDPE) & Alkyd resin \\
\hline
\end{tabular}

The study presents a detailed review about use of waste PET in bituminous concrete mix of flexible pavement and in building concretes.

\section{Polyethylene Terepthalate (PET)}

Polyethylene terephthalate (PET) is thermoplastic in nature. It is also known by "polyester, " which often causes confusion, because polyester resins are thermosetting 


\section{International Journal of Science and Research (IJSR) \\ ISSN (Online): 2319-7064 \\ Index Copernicus Value (2013): 6.14 | Impact Factor (2014): 5.611}

materials. PET is a transparent polymer, with a good mechanical properties and good dimensional stability under variable load. Moreover, PET has good gas barrier properties and good chemical resistance. Above mentioned properties of PET caused its wide application in the form of bottles, thermally stabilized films (e.g. capacitors, graphics, film base and recording tapes etc.) and electrical components. PET is also used for production of fibers for a very wide range of applications in textile industry. PET belongs to a thermoplastic with excellent physical properties. It constitutes is around $18 \%$ of the total polymers produced worldwide and over $60 \%$ of its production is used for synthetic fibers and bottles, which consume approximately $30 \%$ of global PET demand.

\section{Sources of PET Wastes}

Waste PET source can be categorized into three main streams:

a) Bottles- small problems with material recycling; problems related with impurities (e.g. glue on labels), different types additives used during production (e.g. stabilizers, pigments), molecular weight of PET, etc., which are affecting on repeatability of obtained products.
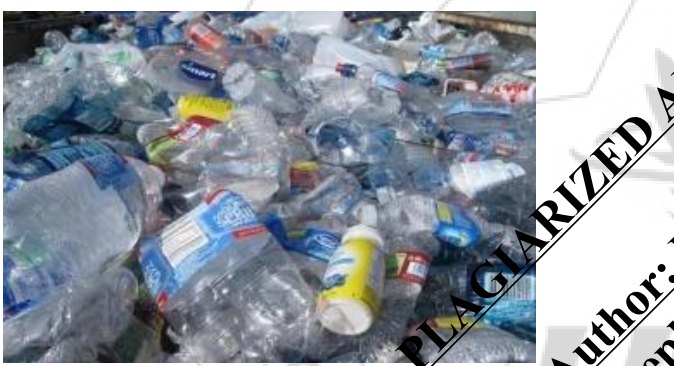

Figure 1: Bottles made of PET

b) Foils- small problems with material re related with additives used during produc(1) pigments), molecular weight of PET, etc. on repeatability of obtained products.

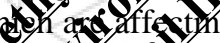
cord from tires c) Cord from tires - huge problem thy recycling. Currently, this fraction of waste as alternative fuel. Example of waste tire coysonted in Fig. 1 and its composition in Table III. and cheap source of vale 1900 y (ethylene terephalate). The main problems cord are contaminatys for round tire rubber and metals.

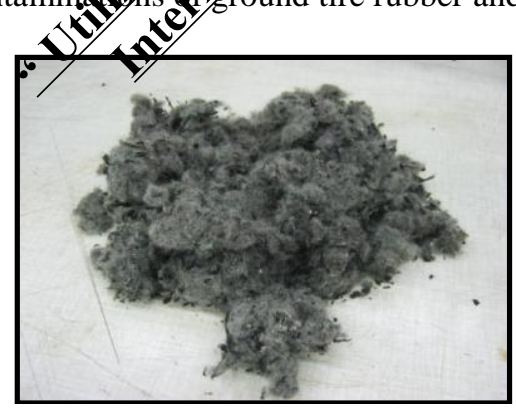

Figure 2: Recycled textile fiber from used tires.

Other methods of overcoming the problems of waste PET through recycling processes may include the incorporation of
PET with asphalt binders as a modifier for asphalt used at road constructions and as reinforcement material for concrete and other building materials by partial substitution for the fine aggregates (i.e. sand). These approaches are usually intended to improve the engineering properties and increase the service life of modified materials. In this way, it appears that it is a viable rout contribution to both achieving economical benefits, and to decrease the environmental impact of waste tire cord.

Table 3: Composition of waste tire cord

\begin{tabular}{|c|c|}
\hline Compositions & Weight \% \\
\hline Polyethylene terephathalate (PET) & 77.60 \\
\hline Polyamide(PA) & 18.70 \\
\hline Polypropylene (PP) & 3.70 \\
\hline
\end{tabular}

\section{Structure and Properties of PET.}

The properties and structure of Polyetrephathatate (PET) are as under:

\section{- Properties}

PET is hygroscopic, meajig it absorbs water from its surroundings. Howeva this "damp" PET is then

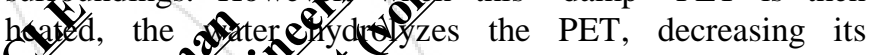
Stilience rosin can be processed in a molding $1 /$ must be dried. Drying is achieved

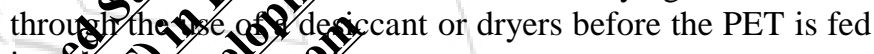

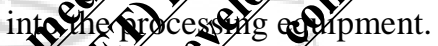

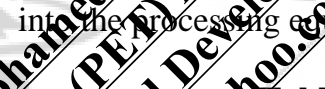

\% $2 \%$ Table 4: Properties of PET

\begin{tabular}{|l|l|}
\hline \multicolumn{1}{|c|}{ Values } \\
\hline Ilimit & \multicolumn{1}{c|}{$2800-3100 \mathrm{MPa}$} \\
\hline Vicat B & $55-75 \mathrm{MPa}$ \\
\hline Linear expansion coefficient $(\alpha)$ & $50-150 \%$ \\
\hline Water absorption $(\mathrm{ASTM})$ & $3.6 \mathrm{KJ} / \mathrm{m}^{2}$ \\
\hline Meting point & $67-81^{\circ} \mathrm{C}$ \\
\hline Boiling point & $82^{\circ} \mathrm{C}$ \\
\hline Density & 0.00007 per $\mathrm{K}$ \\
\hline Solubility in water & 0.16 \\
\hline Molar mass & $>250^{\circ} \mathrm{C}$ \\
\hline & $>350^{\circ} \mathrm{C}($ decomposes $)$ \\
\hline & $1.38 \mathrm{~g} / \mathrm{cm}^{3}$. \\
\hline & Practically insoluble \\
\hline
\end{tabular}

\section{- Molecular Structure}

Polyethylene terephthalate (sometimes written poly(ethylene terephthalate)), commonly abbreviated PET, is the most common thermoplastic polymer resin of the polyester family and is used in fibers for clothing, containers for liquids and foods, thermoforming for manufacturing, and in combination with glass fiber for engineering resins. Its chemical formula is denoted as (C10H8O4)n.

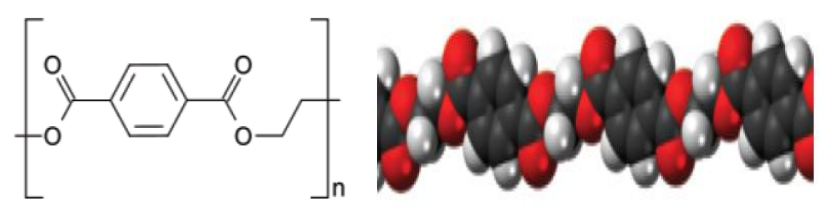

Figure 3: Structure of PET 


\section{International Journal of Science and Research (IJSR) \\ ISSN (Online): 2319-7064 \\ Index Copernicus Value (2013): 6.14 | Impact Factor (2014): 5.611}

\section{Utilization of PET in Flexible Pavements}

Recycling of waste PET plastics can make significant contribution to environment and economy from different aspects. It helps to reduce the exploitation of natural resources to reduce the environmental pollution level, saving energy and money, and it contributes to modifying the physical and engineering properties of construction materials such as asphalt and building concrete. Asphalt has been widely used in road pavement construction as the binder of aggregates. However, it is well recognized that asphalt mixture or coating layer shows severe temperature susceptibility such as high temperature rutting, medium temperature fatigue and low temperature cracking damage (Fig. 2). Therefore, asphalt mixture modification is sometimes used to improve its further application.
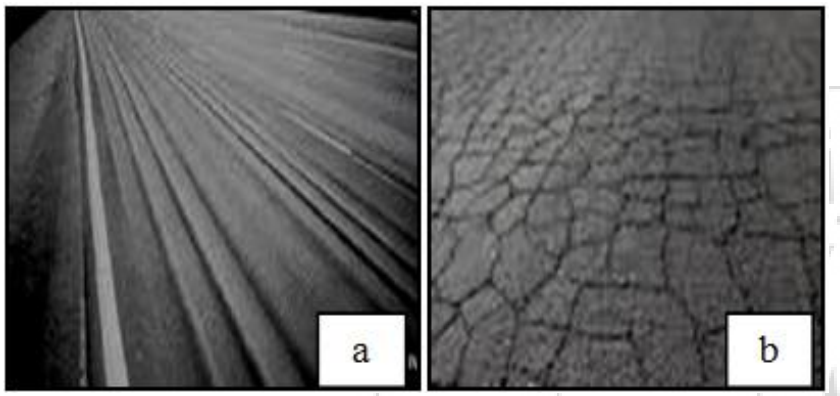

Figure 4: (a) Rutting; (b) Fatigue cracking

Improvements in asphalt properties sometimes achieved by either selecting the proper starting cry by controlling the refinery processes aimed at mas or or asphalts, which are both unfortunately very dicy Therefore, the popular method for impron quality is its modification. Air blowing Fluxing agents or diluents oils are sometimes u the asphalt. Another method that can significa asphalt quality is the addition of pol modification with polymers is a con improvement of rheological properties of resist shove and rutting under long-las o s traffic loading repetitions. Therefore, as kall \$olity should be suitable enough to handle traffes adealately. The lack of stability in an asphalt mixturesean 4 thraveling and flow of the road surface. Flow is of hot mixture asphalt (HMA) pavement to gradual settlements and movements in the without cracking. The

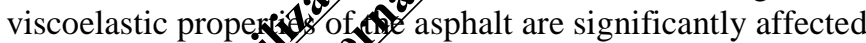
by the chemica1 1 sition and hence they have a direct effect on asphayt peYormance. Pavements defects such as rutting at high temperatures, cracking at low temperature region and others are due not only to traffic loads but also to the capability of the asphalt concrete to sustain temperature changes. Increased traffic factors such as heavier loads, higher traffic volume, and higher tire pressure demand higher performance of road pavements. A higher performance pavement requires asphalt that is less susceptible to high temperature rutting or low temperature cracking, and has excellent bonding to stone aggregates. The uses of virgin polymers in asphalt to improve the characteristics of the resulting polymer modified asphalt have been accomplished for many years. Nevertheless, recently there is an interest in the substitution of commercial virgin material by recycled polymers e.g. shredded waste plastic containers made of PET. Reclaimed rubber obtained from waste tires has been also used with positive effects in pavements. Substitutions technique for asphalt in pavements, including the hot mix and the cold mix by polymers such as PET, is put into practice for the improvement of rutting resistance, thermal cracking, fatigue damage, stripping, and temperature susceptibility. They are used when extra performance and durability are desired. In many cases, they are selected to reduce life cycle costs. Polymer modified binders also show improved adhesion and cohesion properties. The high cost of polymers compared to asphalt means that the amount of polymer necessary for improved pavement performance should be as small as possible. From an environmental and economic point of view, it is possible to imagine the possibility of disposing of waste plastics such as PET bot within road asphalts because similarity in performanceary found between recycled polymers and virgin polymers molitied asphalt. Thus, the use of $\mathrm{CR}$ (crumb rubbery from used tires or thermoplastic polymers such as. PN , or EVA, as an asphalt-modifying agent may contride to solve a waste disposal problem and to nompray the quality of road pavements. Many polykeys de been used as binder modifiers, and they caris es eackith advages difyantages as asphalt modifiers. Qhe main rens mith asphalts with plastics are:

- Otgaining oftofleds at low service temperatures and

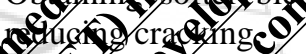

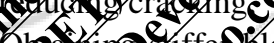

baining stiffoblends at high temperatures and reducing roting $1 \%$

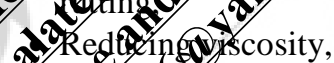

\% 1 redry the stability and the strength of mixtures,

Yoprifying the abrasion resistance and fatigue resistance of dids, and oxidation and aging resistance,

Q Reducing structural thickness and life costs of pavements.

It is well known that polymers can successfully improve the performance of asphalt pavements at almost all temperatures by increasing mixture resistance to fatigue cracking, thermal cracking and permanent deformation.

Use of PET in Flexible Pavements: Utilization of waste polymers in bituminous mixes of flexible pavements was carried out by Vasudevan et al. The methodology was simple author coated the stone aggregates with molten plastics. They concluded that due to plastic coating over aggregates reduced the porosity, moisture absorption and soundness got improved. It was further concluded by them that use of waste plastics in construction of flexible pavements was the right choice and has given a safe passage for disposal of waste polymers. The polymers which were used in modification of bituminous mixes as referred in literature are mainly low density polyethylene (LDPE), high density polyethylene (HDPE), polypropylene (PP), ethylene-vinyl acetate (EVA), acrylonitrile-butadiene-styrene (ABS), Polyethylene terephathalate (PET) and Polyvinyl Chloride (PVC). In 2007 improvement of bituminous concrete was investigated by Awwad and Hbeeb with use of polyethylene (PE). From their studies it was concluded that the best type of polyethylene to be used in bituminous mixes to coat the stone aggregates was low density polyethylene (LDPE), and high density 


\section{International Journal of Science and Research (IJSR) \\ ISSN (Online): 2319-7064 \\ Index Copernicus Value (2013): 6.14 | Impact Factor (2014): 5.611}

polyethylene (HDPE). The analysis of data showed that better engineering properties were achieved by use of grinded high density polyethylene (HDPE) in modification of bituminous mixes. The recommended percentage of additive was $12 \%$ by weight of bitumen content. The stability value was increased, density was slightly reduced and there was a slight increase in air voids and the voids of mineral aggregate. Polyethylene is the most popular and suitable material in the world and is used as additives for bituminous mixes. It possesses excellent chemical resistance, good wear resistance, good fatigue and economical as well. FuentesAudén et al, have concluded that incorporation of polyethylene in bituminous mix should not exceed 5\% by weight of bitumen content because the resulting viscosity will reduce the process-ability of the mixture. Addition of recycled $\mathrm{PE}$ improves the resistance to rutting, cracking and thermal fatigue. García-Morales et al., in their work, have used recycled EVA which was studied varying from 0 to $9 \%$ by weight of bitumen content. Results have indicated that the binder viscosity was increased at higher service temperatures improving road performance like resistance to rutting. Casey et al, have demonstrated that waste HDPE and LDPE were the most suitable and promising recycled materials as compared to recycled PET, PVC and ABS to be used in modification of bituminous mixes. They showed better results can be obtained by using $\mathrm{ABS}$ and also concluded that use of recycled HDPE and LDPE at $4 \%$ by weight of bitumen content is more suitable concentration for bindes modification. A comparative study was performed by Coser et al, for modification of asphalt binder by using dif 9 ent plastic wastes like HDPE, LDPE, ABS, EVS and rumb rubber(CR) to achieve better results for asphal $\mathbf{O}$ inder.

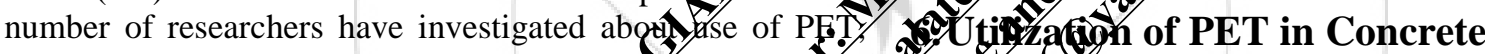
the most abundant waste plastic materia recycling from the household wastes be userys is the most frequently used construction material additive for bituminous binder. The report of the samgry strength, low also published in various publications during entility, heavy weights, and low energy absorption. These The application of PET in the form of gras $\mathrm{mm}$ size was carried out by Hassean eta granules pellet was blended as partial fine $60 / 70$ penetration grade bitumen and grading at a temperature of $140-180^{\circ} \mathrm{Cnd}$. noction was made by using Marshall Hamm win 90 blows on each side. The results obtained in the stydy yed that aggregate replacement of $20 \%$ fine $(2.36-4.75 \mathrm{~mm})$ by volume with PET granules as a effective use to get the highest Marshall Quoti lowest flow and higher stability value. In addon to be the most effective puditives due to its low glass transition tempery semicrystallinity. A number of investigation $s^{6}$ were focused on the influence of fiber additives on the engineering properties of asphalt binder or asphalt mixture. The studies reveal that the mechanical properties of asphalt mixes that include various percentages of PET ranging from $0 \%$ to $10 \%$ with an increment of $2 \%$ were calculated and assessed with laboratory tests. The results showed that the optimum amount of PET was found to be $6 \%$ by weight of bitumen. Additionally, the incorporation of PET has also a significant positive effect on the properties of stone matrix asphalt (SMA) such as increasing viscosity and stiffness of asphalt at normal service temperatures. However, all applied amounts of PET additives did not increase the elasticity of asphalt significantly and on heating, they do not perform satisfactory. Plastic wastes can be used in flexible pavements either in form of aggregate replacement, binder modifier or as mixture reinforcement. The last option was selected by Moghaddam and Karim in their study when they investigated the effects of adding waste PET particles into the asphalt mixture. The results of the study showed that PET reinforced asphalt mixtures had higher stability value in comparison with the virgin mixture. In terms of the convenient quantity of the PET to be added, it was noted that the optimum value in case of stability was $0.4 \%$ PET. Moreover, adding higher amounts of PET into the mixture increased the flow values. In contrast, stiffness of the mixture was decreased, yet fatigue life was increased by adding higher amount of PET. Kalantar et al. (2010), have investigated the possibility of using polyethylene terephthalate as polymer additives in Bitumingus Mix. The binders were prepared by mixing the PET in ormount of $2 \%$, $4 \%, 6 \%, 8 \%$, and $10 \%$ by the weight of gitym bitumen at $150^{\circ} \mathrm{C}$. Results showed better resistance deformations and rutting when compared conventional binders. The result also showed thedddition of PET to bitumen increases the softening 0 intue, and as the higher PET content increases thontung point temperature increases. This phenomeron indes that the resistance of the binder to the effects has increased and it will reduce it ${ }^{2}$ ndency hot weather. Low Density Byethylepe (1) also used in asphalt mixtures as an aggregat It was reported that Marshall Stability was ney bos 50 and mix density was reduced by $15 \%$ the $18 \%$ ment of $30 \%$ LDPE in form of ary 1 with the size of $2.36-5 \mathrm{~mm}$.

points have prompted civil engineers to make use of conventional reinforcement to better the tensile strength and ductility of concrete. The addition of fibers to concrete would act as crack inhibitors and substantially improve the tensile strength, cracking resistance, impact strength, wear and tear, fatigue resistance and ductility of the modified concrete. The concept of using fibers in concrete as reinforcement is not new one. For last three decades numerous studies were performed on Fiber Reinforced Concrete (FRC). In the early $1960^{\text {ee }}$ s only straight steel fibers were used and the major improvement occurred in the areas of ductility and fracture toughness, the flexural strength increases were also reported. In the beginning fiber reinforced concrete was primarily used for pavements and industrial floors. Currently, the fiber reinforced cement composite is being used for wide variety of applications including bridges, tunnels, canal linings, hydraulic structures, pipes, explosion resistance structures, safety valves, cladding and rolled compacted concrete.

Use of PET in Concrete: Studies reveal that the toughness of concrete can be improved by addition of a small fraction usually $0.5-2 \%$ by volume of short fibers to concrete mix during mixing. In the fracture process of fiber reinforced concrete (FRC), fibers stimulates the bridging between cracks in the matrix and thus provide resistance to crack propagation and crack opening before being pulled out or stressed to 


\section{International Journal of Science and Research (IJSR) \\ ISSN (Online): 2319-7064}

Index Copernicus Value (2013): 6.14 | Impact Factor (2014): 5.611

rupture. After extensive studies it is accepted that fiber reinforcement is responsible for improvement in tensile properties of concrete. Some other benefits of FRC are as under:

- Improved fatigue strength

- Wear resistance and

- Durability

- Reduced section thickness

- Cracking can be effectively controlled

- Lighter structure

- Longer life

It has become a common practice to use FRC in various applications like buildings, highway overlays, bridges and airport runways. It is used with traditional steel in load bearing structures. Small quantities of synthetic fibers are generally used in reinforcement for floor slabs in building construction. Many fibers have been used for concrete reinforcement and some are widely available for commercial applications. They include steel, glass, carbon, nylon, polypropylene and others. Studies have indicated that many forms of fibers recovered from various MSW streams are suitable for concrete reinforcement. The recycled fibers are of lower cost as compared to virgin fibers. In addition to the advantages of recycling MSW such as plastics, the incorporation of plastics such as PET wastes in concretes is sometimes essential for the creation of construction buildin materials with a number of characteristics. In prest scenario the role of light weight aggregate has becon very important. The reduction in unit weight of concres. one of the prime goal of concern for earthquake resistat structureat aggresate
However, the cost of artificial lightwe production is high due to requirement of temperature or thermal treatment. Stud 8 , plastic wastes used in light weight PET and PS. The PET bottles were ahead of its high increasing speed of consumption. lot of experimental studies were conducted PET bottles in concrete reinforceperys, construction engineers intend to utiliancete which is produced by partially repladng bement binder with polymer resins. Comparatiy $\%$, thost of polymer concrete resins is still higher thas of because of the high cost of PET bottles recycling combed polyester

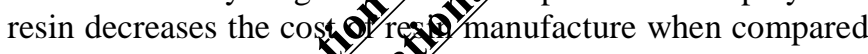
to conventional noyal oyesin production. Unsaturated polyester resin bat onced a good-quality or concrete. However, the cost of producing polymer concrete from waste plastics is still high. The other alternative method reported by Silva et al. in 2005 and Ochi et al. in 2007 propose the use of waste PET bottles in the form of PET fibers to produce a lower-in-cost fiber reinforced concrete. The disadvantage of such method is the small volumetric amount of fiber content in the fiber reinforced concrete which is between $(0.3-1.5) \%$. In this way, only small of such waste may be utilized. Using of shredded waste PET bottles directly as aggregate in the concrete or mortar production is considered the most economical use of waste PET bottles in concrete, thus, provide benefits in waste disposal and reduce pollution of environment since natural mineral aggregates resources remain unused. Limited research has been carried out on using waste PET granules as aggregate in concrete or mortar. In these studies, PET and the other plastic wastes (PE and PP) were used together by partially replacing of mineral aggregates. Marzouk et al. (2007) used waste PET granules as aggregate in lightweight concrete. Authors concluded that, plastic bottles shredded into small PET particles may be used successfully as substitution of aggregates in cement concrete composites. Reuse of PET and other plastics as well as of CR wastes in building industry is an effective approach in both preventing environmental pollution and designing economical buildings. The increase in acknowledging and utilizing environmentally friendly, low cost and lightweight construction materials in building industry call for the need for searching more novel, flexible and versatile composites; as it was proposed in the work. Some researchers, found that the most important aspects of novelty ofight be the development of integrated insulation prods such as waste polymer added mortars, concretes and As a part of this interest, establishment of an appoprile thermal test technique is also a challeng for developing and manufacturing of such prodests. applications concerning 190 ncrete reinforcement particularly for the Portlan center in the last few decades is the incorporymb rubber from used tires (GR). Works W/aste PEF\%o earlier been used in making ightweing to improve concrete mechanical propgres.

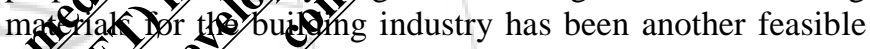

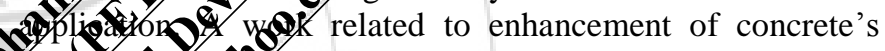
ther performance was carried out using waste

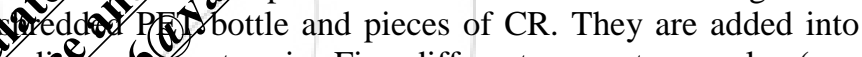

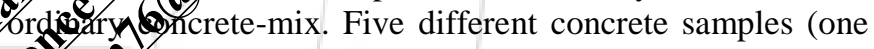
28. thr concretes with waste PET bottle pieces were \$3sidered. Thermal insulation performances of these amples were examined by the adiabatic hot-box technique, recently proposed by the authors. The results revealed that proper addition of selected waste materials into concrete can significantly reduce heat loss or improve thermal insulation performance. The degree of improvement in thermal insulation is found to vary with the added waste material and geometry of shredded-pieces. Flexural strength of concrete is another property of concrete which was an aim of a study by Venu and Rao, They have conducted an experimental investigation on flexural strength of fiber reinforced concrete slabs and compared to plain concrete slabs. They involved the examination of five different slabs two contained steel fibers, two with synthetic macro fibers, namely waste PET and waste HDPP and one plain concrete slab. They were (2.2 $x$ 2.2) $\mathrm{m}$ in size and nominal thickness of $127 \mathrm{~mm}$ after being casted. The authors found that ultimate load carrying capacity of concrete increased by $4.62 \%$ with $1 \%$ HDPP fiber and by $9.11 \%$ with $1 \%$ PET fiber; the compressive strength of concrete increased by $4.2 \%$ with 1\% HDPP fiber and $5.63 \%$ with $1 \%$ PET fiber, and load carrying capacity of concrete in flexure was increased by using both fibers when compared to plain concrete slabs. In a similar issue, flexural behavior of small steel fiber reinforced concrete slabs studied by Ali and Majid. They found that the addition of steel fibers in the concrete improves the energy absorption capacity of slabs. In addition to the aforementioned, Shaikh Faiz Uddin Ahmed et 


\section{International Journal of Science and Research (IJSR) \\ ISSN (Online): 2319-7064}

Index Copernicus Value (2013): 6.14 | Impact Factor (2014): 5.611

al. investigated strain hardening and multiple cracking behavior of hybrid fiber reinforced cement composites containing different hybrid combinations of steel and polyethylene (PE) fibers under four point bending. Consequently, hybrid combination of $1.5 \%$ steel and $1.0 \%$ polyvinyl alcohol (PVA) exhibited best performance in terms of highest flexural strength, $0.5 \%$ steel and $2.0 \% \mathrm{PE}$ exhibited highest deflection and highest energy absorption capacities. The behavior of glass fiber reinforced concrete slabs was studied by Ombres et al. As a result, they found that the ultimate capacity of slabs increases with the amount of GFRP rebars while Andrea and Kanrod found that the compressive strength and ductility are increased by using fibers, when conducting experiments on concrete using different fibers like steel, glass, carbon and hemp.

Ms K. Ramadevi and Ms R. Manju have investigated the possibility of using the waste PET bottles as the partial replacement of aggregate in Portland cement. In their investigation, $0.5 \%, 1 \%, 2 \%, 4 \%$ and $6 \%$ volume of sand was replaced by PET bottle fibers. Based upon the experimental results of this study, the following conclusions were drawn:

- The compressive strength and split tensile strength were increased up to $2 \%$ replacement of the fine aggregate with PET bottle fibers and it gradually decreased for $4 \%$ and $6 \%$ replacements,

- The flexural strength increased up to $2 \%$ replacement the fine aggregate with PET and it gradually decreased ror $4 \%$ and remains the same for $6 \%$ replacements,

- The replacement of the fine aggregate with 2 a bottle fibers was reasonable than other rop PET percentages like 4\% and $6 \%$ as the comprosion and 20, pp. 253-263, 2000.

tensile strength reduces gradually.

Karim et al. studied the structural behavior concrete (PC) beams using PET in the co showed that the beams exhibited higher ductility than base concrete beams, also PC helps in saving energy and in partiallesoly a a tid waste problem posed by plastics. Nibud the Waste Plastic Fiber Reinforced Concret (I) RC several design concrete mixes with $x$ fer 1 percentages $(0 \%$ to $3 \%$ ) of waste plastic fibers. To mons consions based on the results obtained in this

\section{2) 2}

- The workability proy concrete was affected in WPFRC,

- The maximund increase in compressive strength, splitentrength and flexure strength at $1 \%$ of fiber content compared to control concrete,

- The dry density was reduced and made concrete light weight,

- The behavior of WPFRC was found ductile due inclusion of fibers,

- The optimum strength was observed at $1 \%$ of fiber content for all types of strengths.

\section{Conclusions}

The following points can be drawn from the information collected from various scientific literatures are as under:
1)Based on researches, experimental works and scientific reports proved that plastic wastes and especially recycled PET may be applied for modifications of bituminous concrete mix of flexible pavement and also in building concretes.

2) Research studies proved that the properties of flexible pavements were improved, resulting in better performance and stability of road pavement by use of PET in Bituminous concrete.

3) The addition of polymer fibers in concrete works as a reinforcement which in turn improves the performance and strength of concrete.

4)Last but not least the problem of safe disposal of waste plastic materials can be easily solved by utilizing them as a construction material in a eco-friendly way.

\section{References}

[1] U.S. Environmental Protection (USEPA), "Characterization of municipal States," EPA/ $530-S-92$ - Repl., Washington, D.C. 1992.

[2] Franklin Associates It/ " solid waste Updak Pror the USEPA) Prairie Yillage,"

R. Sidoryutib, and K. Inderpreet, "Use of recyed in concrete: A review," Waste d\%ana - 1835-1852, 2008.

Syragnian, "Plastics recycling and waste

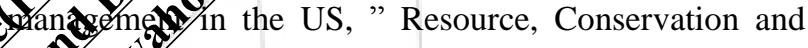
Anderi and R. Manju, "Experimental investigation Q4 The properties of concrete with plastic PET (bottle) Iibres as fine aggregates, " International Journal of Emerging Technology and Advanced Engineering, vol. 2, no. 6, p. 42, 2012.

[6] A. Gawande, G. Zamare, V. C. Renge, S. Tayde, and G. Bharsakale, "An overview on waste plastic utilization in Asphalting of roads, " Engineering Research and Studies Journal, vol. 3, no. 2, pp. 1-5, 2012.

[7] A. S. Jabarin, "Polyethylene terephthalate chemistry and preparation," The Polymeric Materials Encyclopedia, CRC Press Inc., 1996.

[8] L. Menachem and E. Pearce, Handbook of Fiber Chemistry, Second Edition, Marcel Dekker Inc., 1998.

[9] L. Bottenbruch, Engineering Thermoplastics: Polycarbonates, Polyacetals Polyesters, and Cellulose Esters, Hanser/Grander Publications Inc., 1996.

[10] B. Yuonne and M. P. M. R. Yajaira, "Polymer modified asphalt," Vision Technologica, vol. 9, no. 1, pp. 39-48, 2001.

[11] T. B Moghaddam and M. R. Karim, "Properties of SMA mixtures containing waste polyethylene terephthalate," World Academy of Science, Engineering and Technology, vol. 6, pp. 612-622, 2012. 


\section{International Journal of Science and Research (IJSR) \\ ISSN (Online): 2319-7064}

Index Copernicus Value (2013): 6.14 | Impact Factor (2014): 5.611

[12]B. Yuonne and M. P. M. R. Yajaira, "Polymer modified asphalt," Vision Technologica, vol. 9, no. 1, pp. 39-48, 2001.

[13]N. K. Lu, "Effect of astragalus on characteristics of asphalt concrete, " Journal of Materials in Civil Engineering, vol. 11, no. 4, pp. 283-286, 1999.

[14]Z. N. Kalantar, "Properties of bituminous binder modified with waste polyethylene terephtalate," presented at Malaysia Universities Transportation Research Forum and Conferences, December 21, 2010, Universiti Tenaga Nasional.

[15] R. Vasudevan, S. K. Nigam, R. Velkennedy, A. R. C. Sekar, and B. Sundarakannan, "Utilization of waste polymers for flexible pavement and easy disposal of waste polymers, " in Proc. International Conference on Sustainable Solid Waste Management, Chennai, India, pp. 105-111.

[16] M. García-Morales, P. Partal, F. J. Navarro, and C. Gallegos, "Effect of waste polymer addition on the rheology of modified bitumen, " Fuel, vol. 85, no. 7-8, pp. 936-943, 2006.

[17]E. Ahmadinia et al., "Performance evaluation of utilization of waste polyethylene terephthalate (PET) in stone mastic asphalt,"Construction and Building Materials, vol. 36, pp. 984-989, 2012.

[18]Z. N. Kalantar, M. R. Karim, and A. Mahrez," A rodew of using waste and virgin polymer in paye Construction and Building Materials, vol. 33 55-62 2012.

[19] Waste and Resource Action Prog "Annual local authorities plastics 8,1l 2007.

[20] A. Hassan, H. Ganjidoust, and A. A. Ma plastic waste (polyethylene terepholy concrete mixture as aggregates replaceonto 9 . Management's and Research, vol, $28 \%$ 327, 2005.

[21] T. S. Shuler, J. H. Collins e "Polymer modified asphalespons related to asphalt concrete performance, 1 spheology Relationship to Mixture, ASTM O.E, Briscoe Ed ASTM, Philadelphia, 198

[22] N. F. Mogha 1. Aflaki, and M. A. Mohammadi, "Fatigue ${ }_{6}$ of SMA and HMA mixtures," Construct Build Mater, vol. 24, pp. 1158-1165, 2010.

[23] S. E. Zoorab and L. B. Suparma, "Laboratory Design and performance of improved bituminous composites utilizing recycled plastics packaging waste, " in Proc. Technology Watch and Innovation in the Construction Industry, Brussels, Belgium, April 5-6, 2000, pp.203209.

[24] W.J.Tappeinier, "Performance and economical advantage of polymer modified asphalt," Richard Felisinger, Vienna, Austria, 1999.
[25] S. Bose and P. K. Jain, "Laboratory studies on the use of organic polymers in improvement of bituminous road surfacing, " Highway Research Bulletin, vol. 38, 1989, New Delhi.

[26] S. Bose et al., "Characterization of polymer modified asphalt binders for roads and air field surfacing, polymer modified asphalt binders, "American Society of Testing Materials, Philadelphia, USA, pp.331-355.

[27]G. N. King, H. W. Muncy, and J. B. Prudhome, "Polymer modification: Binderes effect on mix properties, " in Proc. the Association of Asphalt Paving Technologists, vol. 55, 1986, pp. 519-540.

[28]R.B. Schmiedlin, "Stone matrix asphalt: The wisconsin experience, " Trans. Res. Record: J. Transs? Res. Board, 1988, pp. 34-41.

[29]B. J. Putman and S. N. Amirkhand "Gtilization of waste fibers in stone matrix asphyres, "Resour Conserv Recc., vol. 42, pp. 265 20140 4.

[30]R. N. Nibudy et al., "Streng andracture properties of

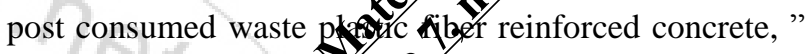
International Journalog Cist, Structural, Environmental and Infrastruction Research and

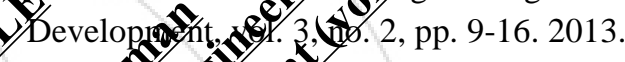

11] K. Ranation 195) propers of concrete with plastic PET (bottle) OHregates, "International Journal of 5 Tology and Advanced Engineering, vol. ef, is ore $6,0.42-46,2012$. Axpron rofile

Brajesh Mishra received the B.E. and M. Tech. degrees in Civil Engineering from Madan Mohan Malviya Engineering College, Gorakhpur, India (Now- MMMUT) in 1988 and KNIT, Sultanpur, India in 2014 respectively. At present working with U.P. Cane Development Department, Lucknow, responsible for construction of road projects. 


\section{Utilization of Recycled Polyethylene Terephthalate (PET) in Engineering Materials: A Review}

M. Sulyman, J. Haponiuk, and K. Formela

Abstract-In general, the quantity of plastics of all types consumed annually all over the world has been growing in a phenomenal way. The manufacturing processes, service
industries and municipal solid wastes (MSW) generate numerous waste plastic materials. The increasing awareness
about the environment has tremendously contributed to the concerns related with disposal of the generated wastes. It is environmental concerns in the world. Due to limited space on landfills and increasing costs of plastics, utilization of waste plastics has become an attractive alternative for disposal. This paper provides a summary of experimental efforts on the
utilization of poly(ethylene terephthalate) (PET) in civil engineering projects, mainly in road pavement, in civil concretes. Presented data indicate that use of waste PET for modification of asphalt, cement and concretes improved their selected properties, which makes economical this approach. usage of new polymeric materials, which has significant efrect on environment pollution (e.g. emission of carbon dioxide, waste disposal problems, etc.

Index Terms - Bitumen, building materials, concrete, PET, recyclins

I. INTRODUCTION

Plastics are commonly used substances which play an important role in almost every aspect of our lives. The widespread generation of plastics waste needs proper end-of-life management. The highest amount of plastics is found in containers and packaging's (i.e. bottles, packaging, cups etc.), but they also are found in durables (e.g. tires, building materials, furniture, etc.) and disposable goods (e.g
medical devices) [1]. Diversity of plastics applications is related with their specific properties, low density, easy processing, good mechanical properties, good chemical resistance, excellent thernal and electrical insulating popt prodection a cost (inconper wide range of applictions. However, in this field two ma direction should be mentioned: 1) using of plastic waste as alternative fuel (burning) in cement kilns and power plants and 2) inaterial recycling of waste polymers.

According to the U.S. Environmental Protection Agency (USEPA 1992), the municipal solid waste (MSW) generated in the United States is $200,000,000$ tons year, anong them bout $38 \%$ wt being paper products, $8 \% \mathrm{wt}$ plastic, and $3 \% \mathrm{wt}$ Manuscript received January 22, 2015; revised May 12, 2015 .
The authors are with the Depar, of The authors are with the Department of Polymer Technology, Chemical
Faculty, Gdansk University of Technology, Poland (e-mail: mainly of PET [7]. as thermoplastic and thermosets.

TABLE H: EXMMPRES OF THERMOPL.STTLS AND THERMOSETTTNO used thernoplastic polyester. It is often called just application in the form of bottles, thernally stabilized films

\begin{tabular}{|c|c|}
\hline Type of plastic & Quantity (1000 tons) \\
\hline Low density polyethylene (LDPE) & 5010 \\
\hline \begin{tabular}{|l} 
High density polyethylene (HDPE) \\
\end{tabular} & 4120 \\
\hline \begin{tabular}{|l|} 
Polypropylene (PP) \\
\end{tabular} & 2580 \\
\hline Polystyrene (PS) & 1990 \\
\hline Polyethylene Terephthalate, (PET) & 1700 \\
\hline the & 3130 \\
\hline
\end{tabular}

In India approximately 40 million tons of the municipal solid waste is generated annually, with evaluated increasing at $12.3 \%$ wt of the total MSW. It is worth to notice, that the most of plastics fraction are drinking bottles which are made

Plastic (polymers) used for applications in bitumen modifications, can be subdivided into two main types depending on their behavior after exposure to heat. First type are thennosetting polymers (e.g. resins, elastomers) which are cured during heating. Three-dimensional structure of cross-linking bonds formed during curing unable sottening of polyner inatrix and its easy re-processing. Second type are thernoplastic polyners. This type of polyners can be shaped and designed in new shapes using heat. In contrary to

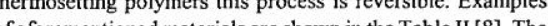
per

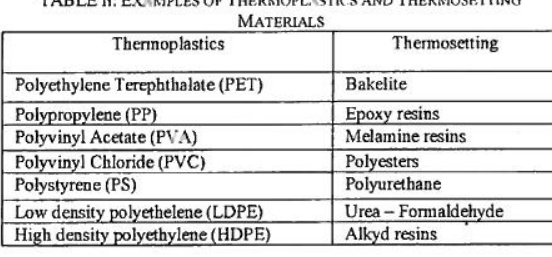
problems related with inptrities (e.g. glue on labels), additives used during production (e.g. stabilizers, pigments),
This paper presents a detailed review about using of was PET in road pavement asphalt and also building concrete.

II. POLYETHYLene Terephthalate (PET)

Poly(ethylene terephthalate) (PET) is the most commonly "polyester," which often causes confusion, because polyester resins are hin asetting nachich polyiner, wh a god good gas barrier properties and good chemical resistance [9]. Abovementioned properties of PET caused its wide (e.g. capacitors, graphics, film base and recording tapes etc.) and electrical components. PET is also used for production of fibers for a very wide range applications in textile industry. PET belongs to a thernoplastics with excellent physical properties [10]. It constitutes is around $18 \%$ of the total polymers produced worldwide and over $60 \%$ of its production is used for synthetic fibers and bottles, which consume approximately $30 \%$ of global PET demand $[11]$

II. SOURCES OF PET WASTES

for concrete and other building materials by partia (i.e. sand) [14]. These approaches are usually intended to improve the engineering

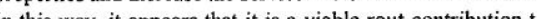
the inironmental impact of waste tire cord.

\begin{tabular}{|c|c|}
\hline $\begin{array}{l}\text { TABLE I: Col } \\
\text { Compositions }\end{array}$ & $\frac{T S T R E C O R D}{\text { Weight percent }(\%)}$ \\
\hline Poly(ethylene therephlhalate) (PET) & 77.6 \\
\hline de (PA) & $\frac{18.7}{37}$ \\
\hline
\end{tabular}

\begin{tabular}{l}
\hline Polyamide (PA) \\
\hline Polypropylene (PP) \\
\hline
\end{tabular}

IV. UtLIZATION OF PET IN ASPHALt PAVEMENT Recycling of waste PET plastics can make significan contribution to environment and econony from differen reduce the enviros and money, and it contributes to modifying the physical and engineering properties of construction materials such asphalt and building concrete

Asphalt has been widely used in road pavement construction as the binder of aggregates [15]. However, it is

well recognized that asphalt mixture or coating layer show Waste PET source can be categorized into three main strean: a) Bottles - sinall problems with material recycling; cerent ter re affecting on repeataility of obtined products. b) Foils mall problens with material recycling; problems related with molecular weight of PET, etc, which are affecting on repeatability of obtained products. c) Cord from tires - huge problem with material recycling. Currently, this fraction of waste PET is used as alternative fuel. Example of waste tire cord is presented in Fig. 1 and is composition in Table III. Waste tire cord can be significant and cheap source of valuable poly(ethylene terephthalate). The man problem during material recycling of waste tire cord are contaminations of ground tire rubber and metals.

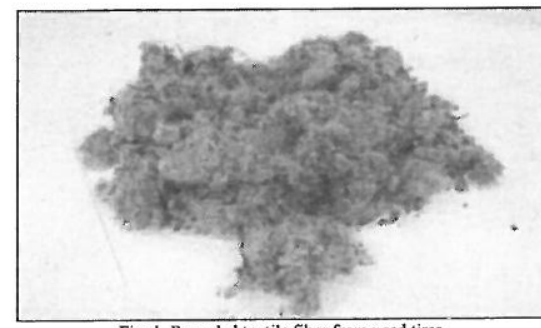

Other methods of overcoming the problems of waste PET PET with asphalt binders as a modifier for asphalt used at road constructions [12], [13] and as reinforcement material utting, metiate susceptiol ta such and high temperature racking dam (Fig. 2). Therefore, asphait mixture acking tamage (Fig. 2). Therefore, asphait tixixtre modification
application.

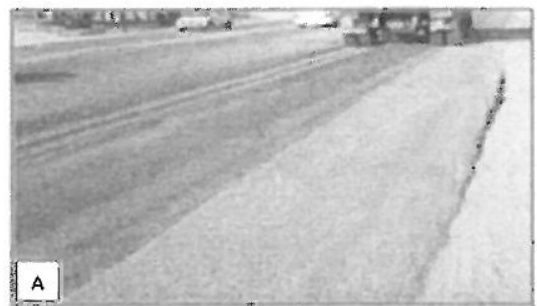

Fig. 2. (A) Rutting; (B) Fatigue cracking [16]

Improvements in asphalt properties sometimes can be chieved by either selecting the proper starting crude oil, or controlling the refinery processes aimed at making desired [17]. Therefore, the popular method for improvenent of 
asphalt quality is its modification. Air blowing makes asphalt soften the asphalt. Another method that can significantly improve asphalt quality is the addition of polymers [17]. Asphalt modification with polymers is a common method improvement of rheological properties of asphalt [18]. A very important property of the asphalt mixture is its
ability to resist shove and rutting under long-lasting traffic and traffic loading repetitions. Therefore, asphalt stability should be suitable enough to handle traffic adequately. The lack of stability in an asphalt mixture means unraveling and aspalt (HMA) pavenent to adjust to gradual settlemints movenents in the subgrade without cracking [19].

The viscoelastic properties of the asphalt are significantly affected by the chemical composition and hence they have direct effect on asphalt performance. Pavements defects such as rutting at high temperatures, cracking at low temperature region and others are due not only to traffic loads but also to the capability of the asphalt concrete to sustain temperature changes. Increased traffic factors such as heavier loads, higher traffic volume, and higher tire pressure demand higher performance of road pavements. A higher perfornance pavement requires asphalt that is less susceptible to high temperature rutting or low temperature cracking, and has Thellent bonding to stone aggregates.

The uses of virgin polymers in asphalt to improve the beecteristics of heresulting polymer modified asphalt have been accomplished for many years [19]. Nevertheless, virgin material by recycled polymers e. shredded waste plastic containers made of PET. Reclained rubber obtained from waste tires has been also used with positive effects in pavements [19].

Substitutions technique for asphalt in pavements, including the hot mix and the cold mix by polymers such as PET, is put into practice for the improvement of rutting resistance, thermal cracking, fatigue danage, stripping, and temperature susceptibility. They are used when extra performance and durability are desired. In many cases, they are selected to reduce life cycle costs [17]. Polyner modified binders a show improved adhesion and cohesion properties [20].

The high cost of polymers conpas to asphalt means that the amount of polymer necessary for improved pavement perfornance should be as snall as poss it is possible to imagine the possibility of disposing of waste plastics such as PET bottles within road asphalts because similarity in perfornance is found between recycled polymers and virgin performance is found between recycled polymers and virgin
polymers modified asphalt. Thus, the use of CR (crumb rubber) from used tires or thernoplastic polymers such as $\mathrm{PE}$, PET, or EVA, as an asphalt-modifying agent may contribute to solve a waste disposal problem and to improve the quality of road pavements [18]. Many polymers have been used as binder modifiers, and they can be classified into a number of groups, each with advantages and disadvantages as asphal modifiers [17].

The main reasons to modify asphalts with plastics are: 1) obtaining softer blends at low service temperatures and
reducing cracking, 2) obtaining stiffer blends at high temperatures and reducing rutting, 3) reduceing viscosity, 4) increasing the stability and the strength of mixtures, 5) mproving the abrasion resistance and fatigue resistance of blends, and oxidation and aging resistance, 6) reducing Iiful hickness and life costs of pavements [21].

fis well known that polymers can successfully improve the peformance of asphalt pavements at almost all temperatures bracking and pernanent deformation [22].

\section{A. Case Studies}

Vasudevan $e t$ al. [23] studied the utilization of waste polyners at production of flexible pavements. In presented wies, authors coated the stone aggregates with molten waste plastics. They concluded that the coating of aggregates with plastics reduced the porosity, absorption of moisture and inproved soundness. They found that the use of waste plastics disposal of waste plastics.

Regarding the use of polymer (plastic) wastes for asphalt modification, those mentioned in the literature are mainly low (HDPE) [25] plene (LDPE) [24], high density polyethylene (EVA) [27], [28], acrylonitrile-butadiene-styrene (ABS) [26] polyethylene terephthalate (PET) [29] and polyvinyl chloride (PVC) [30]. 2007; Awwad and Hbeeb [31] have investigated the improvement of asphalt modified with polyethylene (PE). Their studies have been also carried out to deternine the best type of PE to be used and its proportion in the asphalt mixture. HDPE and LDPE were two types of PE added to coat the aggregate. Data analysis proved that grinded HDPE polyethylene modifier provided better engineering properties. The recominended proportion of the modifier was $12 \%$ by weight of asphalt content. It was also found to increase the stability, reduce the density and slightly increase the air voids the voids of mineral aggregate.

Polyethylene(PE) the most popular plastic material, has Por ere for resistance and low price.

A study on the effect of PE on the modified asphalt properties was conducted by Fuentes-Audén et al [33]. They have concluded that PE incorporation in the asphalt shold not exceed $5 \%$, otherwise the resulting viscosity would reduce the processability of the mixture. Addition of recycled PE promotes better resistance to rutting, cracking and to thernal fatigue.

According to the study of Garcia-Morales et al. [27], the modification of asphalt with recycled EVA led to very satisfying results. In their work, concentrations which were studied ranged from 0 to $9 \%$ wt. The results have also indicated that the recycled EVA has increased the binder viscosity at higher service temperatures, with consequent benefits on road perfornance, such as resistance to rutting. However, the asphalt viscosity at the production and for ictsation temperatures demonstrated to be sufficiently low high as $9 \%$.
Casey et al. [26] have concluded that waste HDPE and LDPE were the most promising recycled materials that can be used for asphalt modification, when compared with recycled
PET, PVC and ABS. They have expected better results to be PET, PVC and ABS. They have expected better results to be obtained with ABS, and pointed out to a concentration of $4 \%$
as the ideal concentration of recycled HDPE and LDPE used as the ideal concentration of recycied

as additives in the asphalt binder.

Comparably, a work done by Costa et al. [34] aimed to evaluate the possible advantages of modifying the asphalt $A B S$ and $C R$ (crub nober), in order to improve the properties of the resulting asphalt binders. The perfornance of modified binders with recycled polymers was compared with that of the conventional asphalt and the one of a commercial modified binder. The characterization of the different asphalts modified with $5 \%$ of each one of the studied polymers demonstrated that it is possible to obtain sinilar properties, or even better, than those of commercial modified asphalt. In fact, it was observed that: SBS, HDPE and EVA are the most promising polymers to increase the softening point of the modified binder; HDPE and EVA are the polymers with higher influence in the penetration test results; SBS, EVA and CR (elastomers) presented the best perfornance in relation to resilience; all modified asphalts, excluding those wih $\mathrm{ABS}$ and $\mathrm{CR}$, only reach the proper including the comercial asphalt; HDPE, LDPE and EVA have a good dispersion in the asphalt, whereas SBS, ABS and $\mathrm{CR}$ are difficult to be melted in the asphalt. This phenomenon was related with viscosity of used modifiers, which were

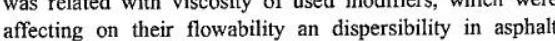
matrix.

PET, the most abundant plastic waste material collected for recycling from the household waste stream as mentioned by Action Program (WRAP) survey [35], may be used as an additive and modifier for asphalt binder. This was investigated by a number of researchers and many reports and scientific studies on this subject were published in the last years.

The application of waste PET; a thermoplastic polymer resin of the polyester family, in the form of granules pellet of $3 \mathrm{nmm}$ size was part of a study carried out by Hassean et al. with an asphalt binder (from 60/70 penetration grade asphalt with an asphalt $12.5 \mathrm{~mm}$ aggregate grading) at $(140-180)^{\circ} \mathrm{C}$ and then compacted it using Marshall hammer with 50 blows on each side. The results obtained in this study proved that the aggregate replacement of $20 \%$ fine aggregate $(2.36-4.75$ $\mathrm{nm}$ ) by volume with $\mathrm{PET}$ granulates ( $3 \%$ total weight of the asphalt mixture) was the effective use to get the highes (hest flow and the highest of stability.

In addition, PET has been found to be the most effective polymer additives due to its low glass transition temperature and semicrystallinity [19].

A number of investigations were focused on the influence of fiber additives on the engineering properties of asphalt bu as a bide. The sigifient disdrantas of SMA mixes belong to the action of water, which penetrates and causes dective spots on the pavement, when stagnating over the oads. The use of anti stripping agents has a linited use only and the process also increases the cost of road construction [37]-[40]. The use of virgin or waste plastics and plastic coated aggregates to inprove the perfornance of asphat asphalt inixes wase done in a number of attents by corporting various types of additives to asphit $30 \mathrm{ch}$ rubber latex, CR, SBS, SEBS, recycled PP, LDPE [41] PE [42] EVA (5\%) [43] and polyolefines [44], [45] Sone of the roperties inproved are durability, fatigue life [46], [47] resistance to rutting, softening point, viscoelastic property [48].

Other fiber modifiers fron the polyester family were anong the modifiers of asphalt, and have obtained more and cercentent improvement effects Cences The mastic asphalt (SMA); it is a type of HMA with open grade fiction concrete (OGFC) [47], [48].

SMA ween [49], [50].

In 2004, a comparison study carried was carried out by Putman and Amirkhanian [51] to investigate the performance f SMA mixtures containing waste $C R$ from used tires, and carpet fibers with commonly used cellulose in one occasion significantly improved the out. The res permanent deformation or moisture susceptibility was foun

Polyester fibers are usually used when strong and durable reinforcements of asphalt-fiber mastics are needed at higher emperatures; as it was reported by Shiuh and Kuei [52]. The inflence of polyester and cellalose fiber additives on the [52]. They have found that polyester fibers and aspalt enhanced the load-carrying ability of asphalt-fiber mastics.

The type of mixing or the process involved in production of very effective asphalt road pavements is very important factor in determining the final product properties. In 1987, an varlable report has implied the successful application of Bonifibers ${ }^{T}$; it is the trade name for polyester fibers of $6 \mathrm{~mm}$ ength manufactured in the city of Tacoma, United States of America and supplied to blend with asphalt. The report stated that in order to assure uniform distribution of Bonifibers the aggregate at the beginning of the dry-mix cycle which lasts at least $15 \mathrm{~s}$ and preferably $30 \mathrm{~s}$ [21].

The assessments of the engineering properties of SMA mixture and the effect of incorporating scrap from waste PET 2012). The moch include various percentages of PET $(0 \%, 2 \%, 4 \%, 6 \%, 8 \%$ and $10 \%$ ) were calculated and assessed with laboratory tests. The results showed that the appropriate amount of PET was found to be $6 \%$ by weight of asphalt. Additionally, the 
incorporation of PET has also a significant positive effect on the properties of SMA such as increasing viscosity and stiffness of asphalt at nornal service temperatures. However,
all applied amounts of PET additives did not increase the elasticity of asphalt significantly and on heating, they'do not perform satisfactory [53].

Using plastic waste materials in road pavement can be either in form of aggregate replacement, binder modifier or mixture reinforcement. The last option was selected by Moghaddam and Karim in their study [13] when they investigated the effects of adding waste PET particles into the
asphalt inixture. The results of the study showed that PET asphalt inixture. The results of the study showed that PET
reinforced asphalt mixtures had higher stability value in compros with the virgin mixture In tem of the

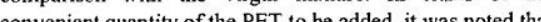
the optimun value in case of stability was $0.4 \%$ PET. Moreover, adding higher amounts of PET into the mixture Moreover, adding higher amounts of increased the flow values. In contrast, stiffmess of the inixture was decreased,

Kalantar et al. (2010) [20], have investigated the possibility of using polyethylene terephthalate as polymer additives in Bituminous Mix. The binders were prepared by mixing the PET in amount of $2 \%, 4 \%, 6 \%, 8 \%$, and $10 \%$ by the weight of optimum bitumen at $150^{\circ} \mathrm{C}$. Results showed better resistance aginst pernanent defornations and rutting
when compared to conventional binders. The result also showed that the addition of PET to bilumen increases the soltening point value, and as the higher $P E T$ content increases the soltening point temperature incress. This phenomenon is increased and it will reduce its tendency to sofen in hot is increas

Low Density Polyethylene (LDPE) was also used in asphalt mixtures as an aggregate replacement. It was reported the Marshall Stability was increased by $250 \%$, and mix density was reduced by $15 \%$ with the replacement of $30 \% \mathrm{LDPE}$ in form of aggregates particles with the size of 2.36-5min [13].

V. Utilization OF WASTE PET IN CONCRETE Concrete is a heterogeneous composite material made up of cement, sand, coarse aggregate and water mixed in a desired proportion based on the strength requirements. Concrete is the most frequently used construction material worldwide. However, it is characterized with a number of defects such as
low tensile strength, low ductility, heavy weights, and low low tensile strength, low ductility, heavy weights, and low energy absorption [54]. These main disadvantages have reinforcement to increase the tensile strength and ductility of concrete.

The addition of fibers to concrete would act as crack inhibitors and substantially improve the tensile strength, cracking resistance, impact strength, wear and tear, fatigue resistance and ductility of the modified concrete. The concep of using fibers in concrete as reinforcement is not new one. For last three decades numerous studies were performed on Fiber Reinforced Concrete (FRC). In the early 1960's only straight steel fibers were used and the major improvement
occurred in the areas of ductility and fracture toughness, the flexural strength increases were also reported. In the fiber reinforced concrete was primarily used for rein forced cement composite is being used for wide variety of ppplications including bridges, tunnels, canal linings, hydraulic structures, pipes, explosion resistance structures, A. Case Studies

A number of scientific reports [56]-[60] concluded that an Afective way to improve the toughness of concrete is adding a the concrete mix during mixing in the fracture process of fiber reinforced concrete (FRC), fibers stimulates the bridging between cracks in the matrix and thus provide resistance to crack propagation and crack opening before being pulled out or stressed to rupture. After extensive studies it is widely reported that such fiber reinforcement can significantly improve the tensile properties of concrete.

Other benefits of FRC include improved fatigue strength, wear resistance, and durability. Using FRC instead of coning tres ber ined in overlays, bridges, and airport runways [57]-[59]. In load bearing applictions it is generally used along with traditional steel reinforcement [61]. In building construction it has become a mere coming practice to use small quantities of yynthetic fiber reinforcement for floor slabs.

Many fibers have been used for concrete reinforcement and some are widely available for commercial applications. They include steel, glass, carbon, nylon, polypropylene and others. Studies have indicated that many forms of fibers recovered from various MSW streams are suitable for concrete reinforcement. The advantages of using such recycled fibers include generally lower cost to process than virgin fibers, an the eliunination of the need for waste disposal in landfills. In ad to to the adro plastics, the incorporation of plasties sch as PET wackes in con chers important characteristics which researches intend to approach in developent of buildingcontruction material The reduction of the unit weight of concrete is one of goals at production of earthquake resistant structures since the earthquake forces are linearly dependant on the mass of the structure [62].

Nowadays, there are many lightweight concrete applications made with natural or artificial lightweight aggregates in the literature [63]-[66]. However, the cost of artificial lightweight aggregate production is high due to requirenent of high incineration temperature or thernal treatment [67]

As an alternative way of creating lightweight concrete, different from the common materials, using waste plastic granules as lightweight aggregate in the production of lightweight concrete was studied. This has attracted much tentits for the resench of a lightweight concrete in an economical way [68]. Some of the plastic wastes used in lightweight concrete were PP, PE, PET and PS. The PET bottles were ahead of the wastes with its high increasing speed of consumption. In few years ago, a lot of experimental studies were conducted on using waste PET bottles in concrete reinforcement [69]-[71]. Nowadays, construction engineers intend to utilize polymer concrete which is produced by partially replacing of cement binder with polyner resins. Comparatively, the cost of materials, because of the high cost of virgin resins. However, waste PET bottles recycling combined with production of polyester resin decreases the cost of resin manufacture when polyester resin decreases the cost of resin production [70]. Unsaturated polyester resin based on recycled PET can be used to produce a good-quality polymer concrete [72]. However, the cost of producing polymer concrete from waste plastics is still high, The other alternative method reported by Silva et al. in 2005 and Ochi et al. in 2007 propose the use of waste PET bottles in the form of PET fibers to produce a lower-in-cost fiber reinforced concrete [56], [73]. The disadvantage of such method is the small volumetric amount of fiber content in the fiber reinforced concrete which is between $(0.3-1.5) \%$. In this way, only small of such wast as bere in the concrete or morter production is as aggregate in the concre us concrete, thus, provide benefits in waste disposal and reduce concreet, hollution of environnent since notural mineral agreduce pollution of environnent since natural mineral aggregates
resources remain unused. Limited research has been carried out on using waste PET granules as aggregate in concrete or mortar. In these studies, PET and the other plastic wastes (PE and PP) were used together by partially replacing of mineral aggregates [74]-[76]. Marzouk et al. (2007) used waste PET granules as aggregate in lightweight concrete. Authors concluded that, plastic bottles shredded into small PET particles may be used successfully as substit

aggregates in cementinous concrete composites [76]. Reuse of PET and other plastics as well as of CR wastes in building industry is an effective approach in both preventing environnental pollution and designing economical buildings. fre incre low cost and lightweight contruction moterials in building flexible and versatile composites; as it was proposed in the work [77]. Some researchers found that the inost important aspects of novelty might be the development of integrated insulation products such as waste polymer added mortars, concretes and bricks [77]-[79]. As a part of this interest, establishment of an appropriate thernal test technique is also a challenge for developing and manufacturing of such products $[80]$

One of the popular applications concerning the concrete reinforcement particularly for the Portland cement concrete in the last few decades is the incorporation of cruinb rubber from used tires (CR). Works [81], [82] presented excellent overviews of such string. Waste PET botles have earlier been used in making lightweight aggregates to improve

PET recycling for forning thermal-insulating materials for the building industry has been another feasible application [83]. A work related to enhancentit of concrete's therm (isulation perfornance was carried out using waste shredded ET bottle and pieces of CR. They are added into ordinary concete-mix. Five different concrete samples (one neat concrete, one concrete with scrap rubber pieces and three che Thamined by the adiabatic hot-box technique, recently proposed by the authors [84]. The results revealed that proper addition of selected waste materials into concrete can ignificantly reduce heat loss or improve thernal insulatio perfornance. The degree of improvenent in therm insulation is found to vary with the added waste material and geometry of shredded-pieces.

Flexural strength of concrete is another property of concrete which was an ainn of a study by Venu and Rao [55], They have conducted an experimental investigation on lexural strength of fiber reinforced concrete slabs and compared to plain concrete slabs. They involved the examination of five different slabs two contained steel fibers, HDPP and size and nominal thickness of $127 \mathrm{~mm}$ after being asted. The athors found that ultimate load carrying capacity of concete increased by $4.62 \%$ with $1 \%$ HDPP fiber and by $9.11 \%$ with $\%$ PET fiber; the compressive strength of concrete increased by $4.2 \%$ with $1 \% \mathrm{HDPP}$ fiber and $5.63 \%$ with $1 \%$ PET fiber, increased by using both fibers when compared to plain concrete slabs.

In a similar issue, flexural behavior of sinall steel fiber reinforced concrete slabs studied by Ali and Majid. They ound that the addition of steel fibers in the concrete improves the energy absorption capacity of slabs [85].

In addition to the aforementioned, Shaikh Faiz Uddin Ahmed et al. [86] investigated strain hardening and multiple of and polyethylene (PE) fibers under four point bending. Consequently, hybrid combination of $1.5 \%$ steel and $1.0 \%$ of highest flexural strength, $0.5 \%$ steel and $2.0 \%$ PE exhibited highest deflection and highest energy absorption capacities. The behavior of glass fiber reinforced concrete slabs was studied by Ombres et al. [87]. As a result, they found that the ultimate capacity of slabs increases with the amount of GFRP rebars while Andrea and Kanrod [88] found that the compressive strength and ductility are increased by using fibers, when conducting experinents on concrete using different fibers like steel, glass, carbon and hemp.

Ms K. Ramadevi and Ms R. Manju [89] have investigated the possibility of using the waste PET bottles as the partial in replaced by PET bottle fibers. Based upon the experinent results of this study, the following conclusion were drawn 1$)$ the compressive strength and split tensile strength were increased up to $2 \%$ replacement of the fine agoregate with PET bottle fibers and it gradually decreased for $4 \%$ and $6 \%$ 
replacements, 2) the flexural strength increased up to $2 \%$ replacement of the fine aggregate with PET and it gradually decreased for $4 \%$ and remains the same for $6 \%$ replacements, 3) the replacement of the fine aggregate with $2 \%$ of PET bottle fibers was reasonable than other replacemen percentages like $4 \%$ and $6 \%$ as the compression and split tensile strength reduces gradually.

Karim $e t$ al. [90] studied the structural behavior of polymer concrete $(\mathrm{PC})$ beans using PET in the concrete. Their result showed that the beams exhibited higher strength and nore PC heps in saing ency and in partily solvigg a solid CC helps in saving encry and in part waste problem posed by plastics.

(We waste plastic fiber (WPRC) by using several design waste plastic fibers. The inajor results obtained in this study as follows: 1) the workability results obtained in property of concrete was affected in WPFRC, 2) the
maximum percentage increase in compressive strength, split tensile strength and flexure strength at $1 \%$ of fiber conten compared to control concrete, 3 ) the dry density was reduced and made concrete light weight, 4) the behavior of WPFRC was found ductile due inclusion of fibers, 5) the optimum strength was observed at $1 \%$ of fiber content for all types of strengths.

VI. Final Remarks

The major remarks based on the infornation gathered from scientific literatures are as follows:

Case studies based on researches and experimental work and scientific reports proved that plastic wastes and especially recycled PET may be applied for modifications of road pavement asphalt and also building concretes.

Case studies proved that inprovements of road pavement aphalt and a lo building concrestes in terns of perfornance in thined by the addition of litte anounts of a number of different polyner binders.

REFERENCES [1] Plastic Common Wastes \& Materials US EPA. (2013). [Online].
Available: www.epa.gov//osw//Conservermaterial/plastic.hth
[2] U.S. Environmental Protection Agency (USEPA), "Characterization of municipal solid waste in the United States," EPA//330-S.92-019 Rep. (31) Franklin Associates Ld., "Characterization of municipal solid waste.

(4) Epdate (Prepared for the USEPA) Prairie Village, "KS, USA, 1998. plastics production, demand and waste data, Brussels, Belgium:
Plastics Europe, 2013. Plastics Europe, 2013 .
R. Siddique, J. B. Khatib, and K Inderpreet, "Use of recycled plastic in
concrete: A review," Waste Management, vol. 28, pp. 1835-1852, concrete A
2008.
(6) P.M.

2008.
P. M. Subramanian, "Plastics recycling and waste management in the
Us." Ressource. Cons ranation and Recycling, vol. 28, pp. 253-263. 2000

K. Ramadevi and R. Manju, "Experimennal investigation on the properties of concrete with plastic PET (botile) fibres as finc
aggregates." International Journal of Emerging Technology and Advanced Engineering, vol. 2, no. 6, p. p2, 2012 .
A. Gavande, G. Zamare, V. . . Renge, S. Tayde, and G. Bharsakale,

[8] A. Gawande, G. Zamare, V. C. Renge, S. Tayde, and G. Bharsakale,
"An overview on waste plastic utilization in Asphalting of rads,"
Engineering Research and Studies Joumal, vol. 3, no. 2, pp. 1-5,
2012. A S Jabarin, "Polyethylene terephthalate chemistry and preparaion," The Polymeric Materials Encyclopedia, CRC Press Inc, 1996. L. Menachem and E. Peare, Handbook of Hiber Che

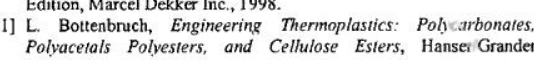
Publications Inc., 1996. 2] B. Yuone and M. P. M. R. Yajaira, "Polymer modified asphalt,"
Vision Technologica, vol. 9, no. 1, pp. 39-48, 2001 . T. B Moghaddam and M. R. Kariu, "'Propeties of SMA mixtures

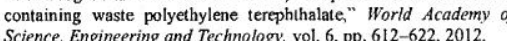
C.Swaptik, T. A. Maniar, and O Suganya, "Polvechylence tereghthe (PET) waste as building solution," Intermational Journal of Chemical, N. Akmal and A. M. Usmani, "Applization of asplat

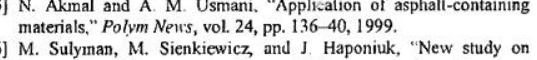
M. Sulynan, M. Sienkiewicz, and I Haponiuk, "New study on
improved performance paving asphatt by crumb rubber and

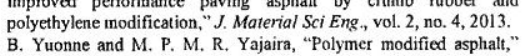

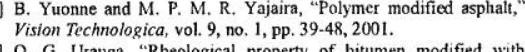
18]
18. G. Uranga, "Rheological property of bitumen
polyethlene and polyehylene based blends," 2008 . polyethylene and polyethylene based blends," "2008.
(19) N N. K. Lu, "Effrect of astragalus an characteristics of asphalt concree,",
Journal of Materials in Civil Engineering, vol. 11, no. 4, pp. 283-286, Z.N. Kalantar, "Propertics of bituminous binder modified with waste polyethylener "terephtalate." presented at Malaysia Universitites
Transportation Research Forum and Conferences, December 21, 2010,

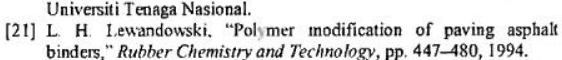
[22] S. Afaki and N. Tabatabaee, "Proposals for modification of Iranian bitumen to meet the clinatic requirements of Iran," Journal of

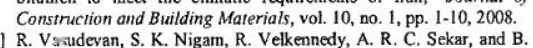
Sundarakannan, "UVtilization of waste polymers for frexible pavement
and easy disposal of waste polymers," in Proc., Intermational Sund easy disposal of waste polymers," in Proce. Intremational
anterence on Sustainable Solid Waste Managemen, Chennai, India, Conference on Sustainable Solid Waste Management, Chennai, India,
pp. 105-111. M. Garcia-Morales, P. Partal, F. J. Navarno, and C. Gallegos, "EFlect of
waste polymer addition on the rheology of modified bitumen." Fuel, E. Hinisloölu and E. Á̃ar. "Use of waste high density polyethylene as bitumen modifier in asphatt concrete mix," Materials Letters, vol. 58 ,

26] D. Casey, C. McNally, A.

of a recycted polymer modifiond, and M. D. Gilchrist, "Development.

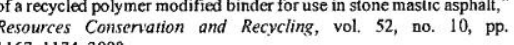

[27] M. Garcia-Morales, P. Panal F. J. Navatro, F. Marinez-Boza,

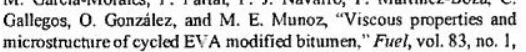
pp. 31-38, 2004. D. Isacsson and X. Lu, "Characterization of bitumens modified with
SEBS, ENA and EBA polymers, Journal of Materials Science, vol. 34,

pp. $3737-3745$, 1999." " "P polyethylene terephthalate (PET) in stone mastic asphath
(PET) Construction and Bulating Materials, vol. 36, pp. 984-989, 2012. Z. N. Kalantar, M. R. Karim, and A. Mahrez," $\mathrm{A}$ review of using wastc
and virgin polymer in pavement," Construction and Building
Matererials, vol. 33, pp. 55-62, 2012."

M. T. Awwad and L. Shbeeb, "The use of polyehylene in hot asphal
mixtures," American Journal of $A_{P}$ lied Sciences, vol. 4, no. 6, pp maxtures, $A m$, 2007

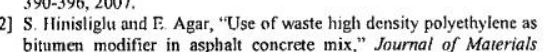
bitumen modifier in asphalt con
letters, vol. 58, pp. 267-271, 2004.

3] C. Fuentes-Audén, J. A Sandoval, A. Jerez, F. J Navaro, F. J. mechanical propertices of recycled polyehylene modified bitumen," Polymer Testing, vol. 27, no. 8, pp. 1005-1012, 2008

34] L. M. B. Cossa, H. M. R. D. Silva, J. R. M. Oliveira, and S. R. M.
Femandes, "Incorporation of waste plastic iv asphate bindes improve their perfonnance in the pavement," Imt. J. Parement Res.
Technol, vol. 6, no. ., p. p. $457-464$, a 2013.
Waste and Resource Action Programme (WRAP). "Annual local

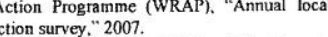
authorities plasticc collection survey." "2007.
[36] A. Hassan, H. Ganjididoust, and A. A. Maghanaki, "Ise of plastic waste (polyethylene terephthalate) in asphalt concrete mixture as aggregates
repplacement, $J$. Waste Managements and Research, vol. 23, no. 4, pp. $322-327,2005$.
T. 2. Shule, J. H. Collins, and J. P. Kirkpoatrick, "Polymer modified

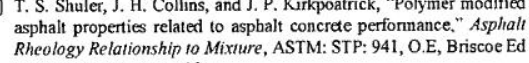

ASTM, Philadelephia, 1987.
[38] N. F. Moghadas, E. Aflaki, and M. A. Mohammadi, "Tatigue belavior
of SMA and HMA mixtures," Construct Build Mater, vol. 24, pp. Ild Mater, vol. 24, pp. [39] S. E. Zoorab and L. B. Suparma, "Laboratory Design and performance
of improved bituminous composites of improved bituminous composites utilizing recycled plastics
packaging waste," in Proc. Techinology Watch and Innovation in the Construction Industry, Brussels, Belgium, April 5-6, 2000, pp. [40] J. H De.

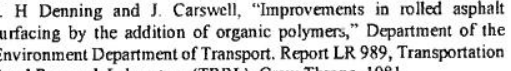
R. J. Salter and F. Rafati-Afshar, "Efffect of additives on bituminous

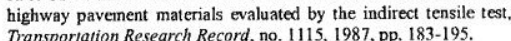

42] D. N. Little, An additive of asphalt additives to reduce permanent
deformation and cracking in asphalt pavements: A brief synopsis of ongoing research," in Proco. the Association of Asphalt Paving
Technologisss, vol. 55, 1986, pp. 314-320. [43] W. I Tappeinier "Perform

modified asphalt," Richard Felisinger, Vienna, austria, 1999 . [44] S. Bose and P. K. Jain, "Laboratory Studies on the use of organic polymers in imporement of bituminous ros
Resarch Bulletin, vol. 38, 1989, New Delhi.

[45] S. Bose et al. "Characterization of polymer modified asphalt binders American Society of Testing Materints, Philadelphia, USA, pp. 331-355.
G. N. King, H. W. Muncy, and J. B. Prudhome, "Polymer modification G. N. King, H. W. Muncy,
Binder's effect on mix properies " in $P$ Pos the Association of Asphal

Paving Technologists, vol. S5, 1986, pp. 519-540.
[47] J. P. Serfass: and J. Samanous, "Fiber-modified asphalt concrete
characteristics, application and behavior," Journal of Association of

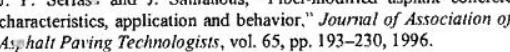
[48] $\mathrm{T}$ T. Surreysa, $\mathrm{O}$. Halit. and $\mathrm{A}$. Atakan, "Investigation of rutting
nefformance of asphait mixtures containing polymer modifiers," performance of asphath mixtures containing polymer modifiers,"
Constr Build Mater, vol. 21, no. 2, pp. 328-37, 2007. 149] M. L. Asi, "Laboratory comparison study for the use of stone matrix asphalt in hot we wa
9882-989, 2006 .

982-989, 2006.
(50) R. B. Schniedlin, "Stone matrix asphalt: The wisconsin experience,"
Trans Res. Record: J. Trans. Res. Board, 1988, pp. 34-41.

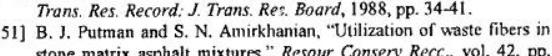
stone matrix asphalt mixtures," Resour Conserv Recc., vol. 42, pp.
265-274, 2004. 21]. Shiuh and L. Kuie-Yi, "Mechanisms and behaviour of bitumen
strength reinforcement using fibers,"J. Mater. Sci, vol. 40, pp. 87-95,

33) E. Ahmadinia et al., "Performance evaluation of utilization of waste polyethylene terephthalate (PET) in stone mastice asphalt,"
Construction and Building Malerials Journal, vol. 36, pp. 984-989, [54] R. R. N. Nibudy e al, "Strength and fracture properties of post cinsumed
waste plastic fiber reinforced concrete," "Inemational Journal of Civil. Structural. Environmental and Ihrrastructure
and Development, vol, 3, no. 2, pp. $9-16.2013$

[55] V. Malagavelli and P. N. Rao, "Effect of non-degradable waste in concrete slabs," Imtermational Journal of
Engineering, vol. 1, no. 3, pp. 449-457, 2010.

Engineering, vol. 1, no. 3, pp. 449-457, 2010 .
[56] D. A. Silva, A. M. Betioli, P. J. P. Gleize, H. R. Roman, L. A. Gomez,

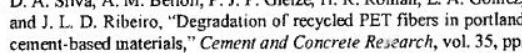
cement-based materials," Cement and Concrele Reszarch, vol. 35, pp.
1741-1746, 2005.

[57] American Concrete Institute (ACD), "Slate-of-the-art report on fiber
reinforced concrete," Commintee 544 Rep.. ACI 544.18 -82, Detroit,
Concreeter Techinology and Design, Surrey University Press, vol. 2, pp
2-105, 1984 . A. Bentur and S. Mindess, Fiber Reinforced Cementitious Compositess

60] Y. Wang, S. Backer, and V. C. Li, 'An experimental study of synthetic

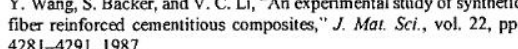
4281-4291, 1987. Intitute (ACI), "Design consideration for steel
American Concrete Institus

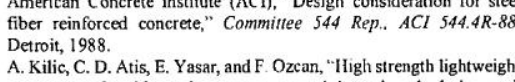

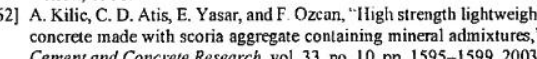

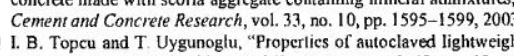
aggregate concrete," Building and Environment, vol. 42, no. 12, pp
$4100-4116,2007$. 64] D. S. Babu, G. K. Babu, and T. H. Wee, "Properties of lightweight
expanded poly styrene aggregate concretes containing ly ash," Cement expanded pol, styrene aggregate concretes containing Oy ysh," Cement
and Concrete Research, vol. 35 , pp. 1218-1223, 2005. [65] E. Yasar, C. D. Atis, A. Kilic, and II. Gulsen, "Strength properties of lightweight concrete made with basaltic pumice and fly ash,"
Materials Letlers, vol. 57 , pp. $2267-2270,2003$. 66] R. Demirirbogaza and R. Gill, The effects of expanded pertite aggregate. silica fume and fly ash on the themal conductivity of lightweight
concrete," Cement and Concrete Research, vol. 33, pp. 723-727, concrete," Cement and Concrete Ressarch, vol. 33, pp. 723-722, 67] I. B. Topcu, Concrete Technology, Ugur Press, Eskisehir, Turkey, [68] H. Koide, M. Tomon, and T Sasaki, "Investigation of the use of waste plastic as an aggregate for lightweight concres.
Construction, London, pp. 177-186, 2002.

[69] A. A. Abdel-Azin, "Unsaturated polyester resins from polyyctilylen Science, vol. 36, no. 24, pp. 2973-2977, 1996.
KS. Rebeiz D.

K.S. Rebeiz, D. W. Fowler, and D. R. Paul, "Making polymer concrete 1991 .

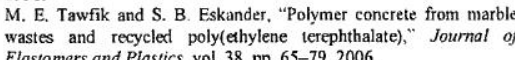
A

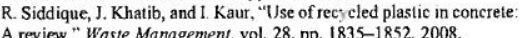

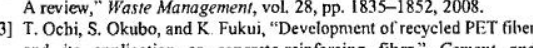
and its application as concrete-ereinforcing fiber." Cement and
Concrete Composites, vol. 29, pp. $448-455$, 2007. C. Yun-Wang, M.Dae-Joong, C. Jee-Seung, and C. Sun-Kyu, "Effects
of waste PET bottele aggregate on the propertics of Conncrete," Cement
and Concrete Research, vol. 35, pp. 776-781, 2005

(75) S. Gavela, C. Karakossa, C. Nydriotis, V Kaselouri-Rigopoulon, S.

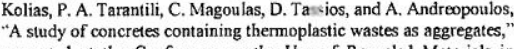
A sudy of concretes containing themmoplastic wastes as aggregates,
presented at the Conference on the Use of Recycled Materials in Building and Structures, Barcelona, Spain, 2004.
O. Y. Marrouk, R. M. Dheilly, and M. Queneudec, "Valorization of

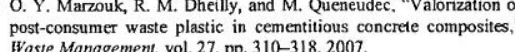
Waste Management, vol. 27, pp. 310-318, 2007. perfornances of newly der
vol. 40, pp. 679-88,2008.

178] B. Yesilata and P. Turgu, "hisulation property of nibecized

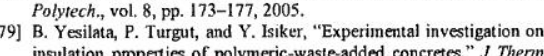
insulation properties of polymeric-wast
Sci. Technol, vol. 26, pp. 15-20, 2006

for comparing thernal insulation perfonamic measurement technique

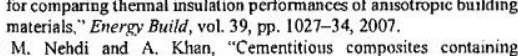

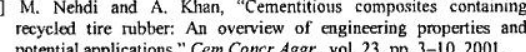
potential applications." Cem Concr Aggr., vol. 23, pp. 3-10, 2001. scrap-tire rubber - An overviev," Waste Manage, vol. 24, pp. 563-569, 183] S. Nienhuys, "Plastic waste insulation for high altitude areas."
Unofficial Report, Senior Renewable Energy Advisor, SNV-Nepal, 26 
[84] B. Yesilata, Y. Isiker, and P. Turgut, "Thermal insulation
enhancement in concretes by adding waste PPT and nuber pieces." Construc ion and Building Materials, vol. 23, pp. 1878-1882, 2009. A R Khaloo and M Alshart, "Cement and concrete composite," 6] S. Faiz U. Ahmed, M. Maale, and P. Parmasivam, “"Construction and building materials, EL.CEVIER Joumals, vol. 21, pp. 1088-1097. 2007. $\mathrm{O}$. concrete slabs reinfored with GFRP rebars" Intermational Meeting on
Compostre Materials. PLAST 2000, Milan, Italy, pp. 243-250.

18. Andrea and B. Kanrod, "Fiber added concrete," presented at $2 n$

[89] K. Ramadevi and R. Manju, "Experimental investigation on the (ntregates." International Joumal of Emerging Technology and Advanced Engineering, vol. 2, issue 6, pp. 42-46, 2012.

90] K. S. Rebeiz, S. P. Serhal, and D. W. Fowler, "structural behavior of polymer concrete bents R. N. Nibudey, P. B. Nagamaik, D. K. Parbat, and A. M. Pande, Strength and fracture properties of post consumed waste plastic fiber Emitronmental and Infrastrucure Engineering, Structural Derelogment (IJCSEIERD), vol. 3, issue 2, pp. 9-16, 2013.

Mohamed Sulyman was bom in 1976. He got his tudies and the B.Sc. degree in 2000 from Al-Mergheb University in the field of chenica

Polymer Technology Department, Gdanisk University

of Technology in Poland. His area of research
Jozef Haponiuk was borm in 1950. He obtained his Leuna Merscburg, Gernany. Since 2006 he is the

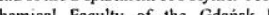
Technology. His special scientific iverssty of chemistry, characterization and processing of polyurethanes, recycling of polymers and rubber, Krzysztor Formcla was bom in 1986. He obtaine his PhD title in 2014 from Chemical Faculty, Gdansk University of Tethnology (Poland). He is employed
at the Polymer Technology Department at the Chemical Faculty Gdansk University of Technology since 2014. Cuntently heis an assistant professor. His scientific interests are polymer chemistry and
technology, polymer processing (especially extrusion technology, polymer processing (ess
and blending of polymers) and recycling of waste nubber. 